U.S. Department of Energy Title Page Form Maker v1.0

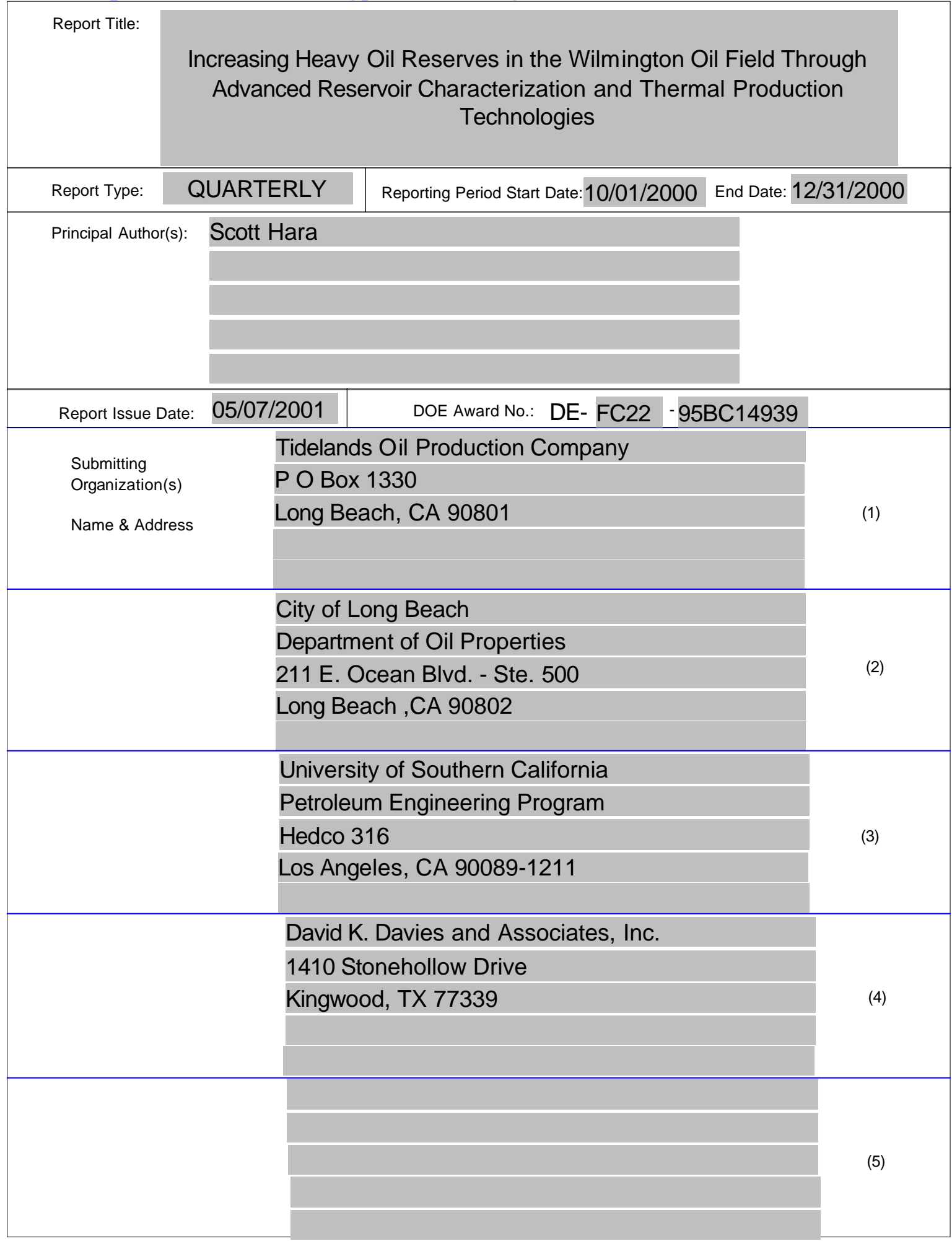




\section{INCREASING HEAVY OIL RESERVES IN THE WILMINGTON OIL FIELD THROUGH ADVANCED RESERVOIR CHARACTERIZATION AND THERMAL PRODUCTION TECHNOLOGIES}

Cooperative Agreement No.: $\quad$ DE-FC22-95BC14939

Contractor Names: $\quad$ City of Long Beach Department of Oil Properties (City) and Tidelands Oil Production Company (Tidelands), Long Beach, CA.

Date of Report: $\quad$ May 7, 2001

Award Date: $\quad$ March 30, 1995

Anticipated Completion Date: $\quad$ March 29, 2001

DOE Award:

$\$ 6,097,897$ (Cum Actual through December 2000) $\$ 700,000$ (2000 Projected) $\$ 235,000$ (December 2000 YTD Actual)

Principal Investigator: $\quad$ Scott Hara - Tidelands

Program Manager: $\quad$ Gary Walker - National Petroleum Technology Laboratory

Reporting Period: $\quad$ October 1, 2000 to December 31, 2000 


\section{Objectives}

The project involves using advanced reservoir characterization and thermal production technologies to improve thermal recovery techniques and lower operating and capital costs in a slope and basin clastic (SBC) reservoir in the Wilmington field, Los Angeles Co., Calif.

\section{Summary of Technical Progress}

Through September 2000, project work has been completed on the following activities: data preparation; basic reservoir engineering; developing a deterministic three dimensional (3-D) geologic model, a 3-D deterministic reservoir simulation model and a rock-log model; well drilling and completions; and surface facilities on the Fault Block II-A Tar Zone (Tar II-A). Work is continuing on improving core analysis techniques, final reservoir tracer work, operational work and research studies to prevent thermal-related formation compaction in the Tar II-A steamflood area, and operational work on the Tar V steamflood pilot and Tar II-A post steamflood projects. Work was discontinued on the stochastic geologic model and developing a 3-D stochastic thermal reservoir simulation model of the Tar II-A Zone so the project team could use the 3-D deterministic reservoir simulation model to provide alternatives for the Tar II-A post steamflood operations and shale compaction studies.

The project team spent the fourth quarter 2000 performing well work and reservoir surveillance on the Tar II-A post-steamflood project and the Tar $\mathrm{V}$ horizontal well steamflood pilot.

Expanding thermal recovery operations to other sections of the Wilmington Oil Field, including the Tar $\mathrm{V}$ horizontal well pilot steamflood project, is a critical part of the City of Long Beach and Tidelands Oil Production Company's development strategy for the field. The current steamflood operations in the Tar V pilot are economical, but recent performance is below projections because of wellbore mechanical limitations that are being evaluated. See Operational Management for more details.

\section{Reservoir Simulation}

The original intent of the 3-D advanced reservoir modeling work was to address the lateral variations in rock geology using geostatistical correlation methods. Upon completion of the geostatistical work, the plan was to rebuild the 3-D deterministic geologic model and examine various stochastic realizations of reservoir conceptual models for simulation purposes. The STARS ${ }^{\mathrm{TM}}$ thermal reservoir simulation program by the Computer Modelling Group (CMG) of Calgary and the R10,000 Onyx RE2 work station by Silicon Graphics Incorporated (SGI) were selected for the reservoir simulation modeling which began in October 1996. History matches covering the primary depletion, waterflood, and steamflood periods were completed for the 3-D deterministic thermal reservoir simulation model in June 1998.

The City of Long Beach modified the project priorities in the third quarter 1998 to address their concerns about steamflood-related surface subsidence and how to safely operate the Tar II-A wells during the post-steamflood phase. The 3-D deterministic 
reservoir simulation model was immediately used to optimize oil production while accelerating steam chest fill-up with flank water injection by measuring the mass fluid and heat balance effects as they pertained to reservoir pressure. Reservoir pressures in the target area are affected by the following occurrences: mixing of the hot and cold fluids at the flank water injection sites; continuous heat loss in the mature steamflood area to the overburden and underburden formations; steam chest collapse and expansion in the structurally updip areas; and the movement and production of hot fluids throughout the steamflood project area. Taken together, these parameters make the prediction of reservoir pressures too difficult without a viable reservoir model. The post-steamflood reservoir simulation modeling study was the basis for a technical paper presented at the AAPG / SPE Western Regional Meeting in June 2000.

The real-time response capability of the reservoir simulation model has made it an indispensable tool for day to day reservoir management purposes. The model performed its primary function of setting injection and production rates and predicting when steam chest fill-up would occur. The model can effectively predict overall mass and heat balance of the injected and produced fluids, provided it is updated with actual data. The model cannot predict net oil production and did not provide the correct steam chest fill-up pressure or the short term injection to production ratio to use following steam chest fill-up. These model weaknesses will probably require a stochastic 3-D model to correct.

The plan is to adapt the 3-D deterministic model for use on the Tar $\mathrm{V}$ horizontal well steamflood pilot project and to update the Tar II-A model.

\section{Reservoir Management}

The Tar II-A steamflood project was terminated in January 1999 when the project lost its inexpensive steam source from the Harbor Cogeneration Plant as a result of electric power deregulation in California. An operational post-steamflood plan was developed and implemented to mitigate the effects of the lost steam injection and possible thermal-related formation compaction by injecting cold water into the flanks of the steamflood. The purpose of flank injection has been to increase and subsequently maintain reservoir pressures at a level that would fill-up the steam chests in the "T" and "D" sands before they could collapse and cause formation compaction and to prevent the steam chests from

reoccurring. A new 3-D deterministic thermal reservoir simulation model provided operations with water injection rates and allowable production rates by well to minimize future surface subsidence and it accurately projected reservoir steam chest fill-up by October 1999. A geomechanics study and a separate reservoir simulation study have been performed to determine the possible causes of formation compaction, the temperatures at which specific compaction indicators may be affected and the projected temperature profiles in the over and underburden shales over a ten year period following steam injection. Further geomechanics work is planned.

Steam chest fill-up of the "D" sands occurred in September 1999 when the pressure throughout most of the reservoir exceeded $90 \%$ hydrostatic or about $960-1000$ psi. The reservoir then acted more like a waterflood that could be operated at lower Injection to production ratios $(\mathrm{I} / \mathrm{P})$ and net injection rates. However, maintaining reservoir pressure is important to prevent steam chest reoccurrence. In mid-September 1999, net water injection was reduced substantially in the " $D$ " sands and reservoir pressure plummeted about 100 psi within six weeks. Starting in late-October 1999, net "D" sand water injection 
was increased and reservoir pressure rose back to steam chest fill-up pressure of $90 \%$ hydrostatic pressure by March 2000. Reservoir pressure has been maintained and in December 2000 averaged 89\% hydrostatic. After reaching fill-up in October 1999, net "T" sand injection remained at a high rate through April 2000 and reservoir pressures stabilized at $98 \%$ hydrostatic pressure. The objective is to lower "T" sand pressure slowly to $90 \%$ hydrostatic. Net injection was reduced and "T" sand reservoir pressure averaged $96 \%$ hydrostatic in December 2000.

A reservoir pressure monitoring program was developed as part of the poststeamflood reservoir management plan. This bi-monthly sonic fluid level program measures the static fluid levels in all idle wells an average of once a month. The fluid levels have been calibrated for liquid and gas density gradients by comparing them with a number of wireline downhole Amerada bomb pressures taken within a few days. This data allows engineering to respond quickly to rises or declines in reservoir pressure by either increasing injection or production or idling production.

\section{Operational Management}

The Tar II-A project averaged 1,026 BOPD and 19,366 BPD gross fluid (18.88 water-oil ratio [WOR]) with 28,354 BPD water injection in the Fourth Quarter 2000. These rates compare with 1,014 BOPD and 20,184 BPD gross fluid (19.91 WOR) with 28,947 BPD water injection during the previous quarter and 1,000 BOPD and 19,361 BPD gross fluid (19.36 WOR) with 31,410 BPD water injection for the year.

Oil production was initially optimized by operating the highest oil cut wells prior to post-steamflooding with a maximum gross fluid rate of 7,000 BPD based on reservoir simulation modeling. Actual production during the first four months of post-steamflood operations from February-May 1999 averaged 733 BOPD and 6,919 BPD gross fluid (9.44 WOR) from ten wells with corresponding water injection averaging 28,160 BPD. Wells that reach $98 \%$ water cut are idled and wells that were idled at the end of the steamflood phase are activated one at a time to maintain total gross production rates and evaluated. Oil production increased during the quarter without a change in gross fluid production because two of the best wells, UP-941 and UP-942, were activated following a year of downtime to accommodate the surface land owner's development project. Wells UP-912 and UP-910 were idled to offset the additional production and because they had the highest water cuts. With the steam chest filled and reservoir pressured stabilized at about $90 \%$ hydrostatic or higher for over a year, the plan is to increase well work activity to increase production and injection. Acid stimulation jobs are planned on selected producers to remove wellbore scale and increase oil cuts. Selected injection work will be performed to improve profile control by cleaning out scale and sand fill or mechanically isolating water to desired sands. Several producers with good oil production potential but requiring workovers will be activated. Former steam injectors located structurally downdip will be activated as water injectors to restore project injectivity to above 35,000 BPD and to distribute water more evenly along the flanks to reduce water breakthrough to the producers.

Expanding the DOE project in March 1999 to include the Tar V steamflood has allowed the project team to continue research related to the Tar II-A horizontal well pilot steamflood operations. The Tar V pilot steamflood began in June 1996 and initially included two new horizontal steam injectors (wells FJ-202 and FJ-204), two existing vertical water injectors (wells FR-111 and FRA-83), three new horizontal producers (wells 
$\mathrm{J}-201, \mathrm{~J}-203$ and J-205), and three existing vertical well producers (wells A-186, A-195 and A-320). The steamflood project wells are completed in the Wilmington Field Fault Block V Tar Zone "S" sands as shown in the "S4" Sand structure map in Figure 1. Well FRA-29 was converted to a water injector in November 2000. A new horizontal producer, $\mathrm{J}-206$, is being proposed to drill in 2001 along with converting a south flank well to water injection for additional pressure support (both shown in red).

Pilot steamflood performance was excellent for the first two years as shown in Figure 2 with oil production peaking at 743 BOPD in January 1998 at a cumulative steam-oil ratio (SOR) of 4.4. All five horizontal wells were given initial cyclic steam jobs to consolidate the formation sands and to stimulate heavy oil production. For the five horizontal wells, Table 1 lists the initial production date, the peak monthly oil production rate, the date of peak oil production, and the cumulative oil production through December 2000. The three infill vertical wells, $A$ 186, A-195 and A-320, all responded favorably to steam injection in the horizontal wells. Wells A186 and A-320 still contributed a combined 108 BOPD in December 2000. Well A-195 was idled in August 1998 because of steam breakthrough.

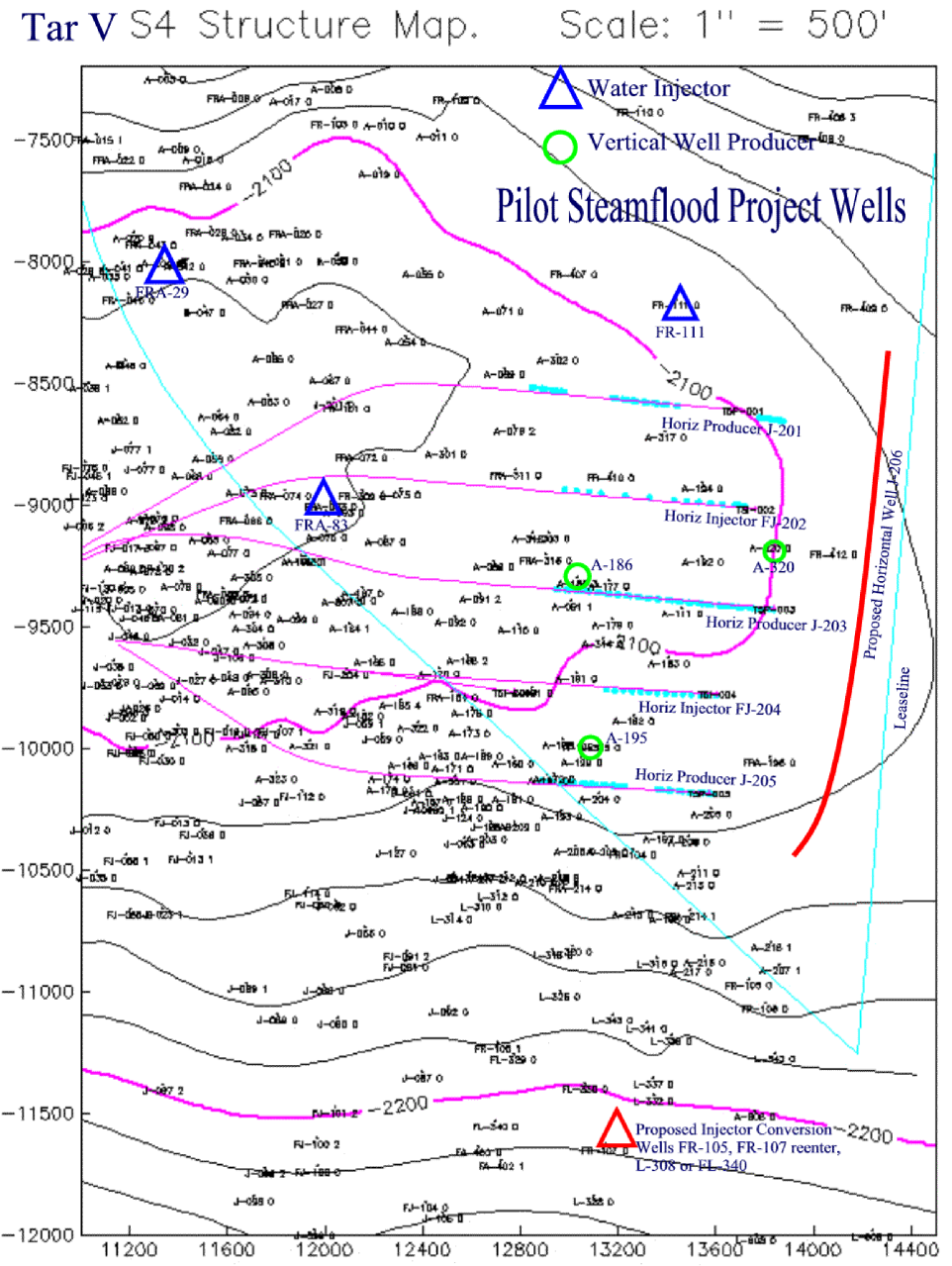

Figure 1

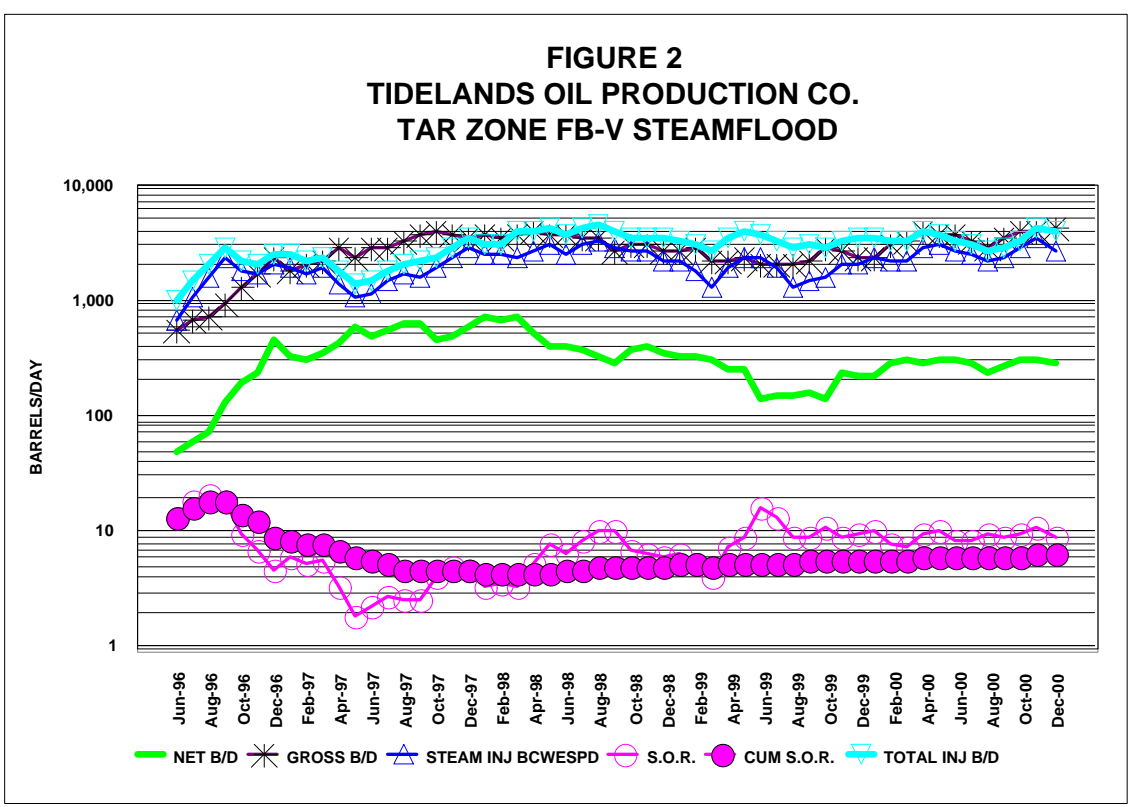




\begin{tabular}{||c|c|c|c|c||}
\hline \multicolumn{5}{|c|}{ Tar V Steamflood Pilot - Horizontal Wells } \\
\hline \hline Well & Init Prod Date & $\begin{array}{c}\text { Peak Prod, } \\
\text { BOPD }\end{array}$ & $\begin{array}{c}\text { Peak Prod } \\
\text { Date }\end{array}$ & $\begin{array}{c}\text { Cum Oil Prod Thru } \\
\text { Dec 00, 1000 BO }\end{array}$ \\
\hline FJ-202 & Nov 96 & 280 & Dec 96 & 40.8 \\
\hline FJ-204 & Feb 97 & 223 & Apr 97 & 27.0 \\
\hline J-205 & Apr 97 & 328 & May 97 & 80.0 \\
\hline J-203 & Jun 97 & 267 & Mar 98 & 148.1 \\
\hline J-201 & Oct 97 & 283 & Jan 98 & 85.9 \\
\hline Note: Wells FJ-202 and FJ-204 converted to injection Jun 97 and Oct 97, respectively. \\
\hline \hline
\end{tabular}

After reaching peak production of 743 BOPD in January 1998, the pilot project oil production declined significantly to a low of 148 BOPD in October 1999 for various reasons including lower steam injection rates than planned, well downtime from sand control problems, and gross production restrictions to meet new injection to production ratio (I/P) requirements for surface subsidence control. Restricting gross production rates became a problem because the horizontal producers began responding to steam and water injection that resulted in higher producing fluid levels and water cuts. Steam injection to the pilot project was increased in October 1999 and well work was performed to repair two of the horizontal producers for sand control and to convert one vertical well to water injection. This work resulted in oil production rising to 304 BOPD in December 2000 with a cumulative SOR of 6.4.

The projected oil reserves for the pilot project is 1.7 million barrels assuming the use of 8.5 million barrels of cold water equivalent steam and 16.7 million barrels of total steam and water injection over 14 years. As of December 2000 or 4.5 years, the pilot has produced 586,000 barrels of oil and $4,863,000$ barrels of gross fluid $(88 \%$ average water cut) and injected $3,726,000$ barrels of steam and 5,197,000 barrels of total steam and water for an overall I/P ratio of 1.07. The steamflood performance curves in cumulative barrels vs time for oil production. gross fluid production, steam injection and total steam and water injection are shown in Figure 3.

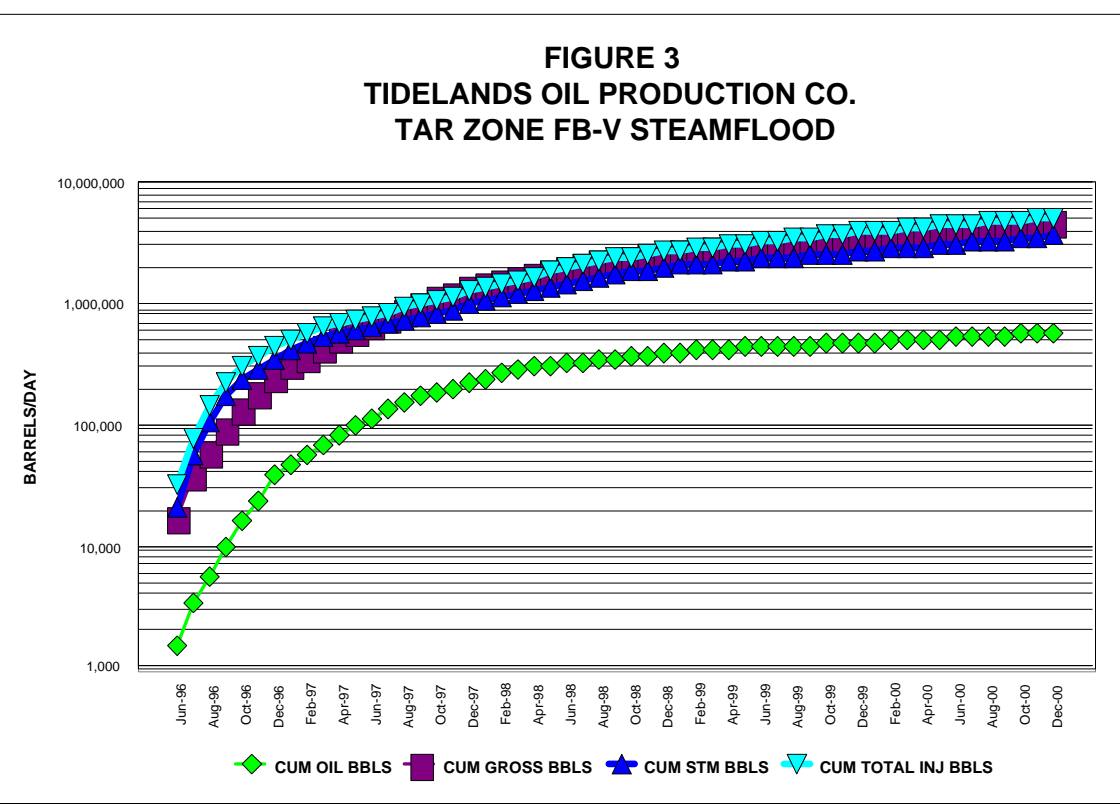


The pilot project to date is meeting the original reservoir engineering projections based on oil recovery vs cumulative gross fluid production and cumulative steam injection. The original pilot projections show that to recover 586,000 barrels of oil would require producing 4,990,000 barrels of gross fluid (actual is 2.5\% lower) and injecting 3,643,000 barrels of steam (actual is 2.3\% higher). However, the project is behind schedule because of the low rates of production and injection. Based on the original projected volumes, the project should have recovered 586,000 barrels of oil by the second quarter of 1998 .

The Tar $\mathrm{V}$ pilot project has been operated differently than originally planned because of thermal-related surface subsidence concerns regarding the Tar II-A steamflood project. Steam and water injection were increased to raise the average I/P ratio to 1.05, compared to the originally planned I/P ratio of 0.75 during the first four years of the project. The planned I/P ratio was lower because the Tar II-A project averaged a $0.75 \mathrm{l} / \mathrm{P}$ ratio from 1990 to 1994 without any apparent adverse surface subsidence effects. The reason a lower $\mathrm{I} / \mathrm{P}$ ratio in a steamflood was considered safe is because injected high temperature steam displaces much more volume than its cold water equivalent volume, up to 35 times more at 800 psi reservoir pressure. The change in plan accelerated steamflood and waterflood response, hence the high producing fluid levels in the wells. Because the horizontal producers are completed at the bottom of the S4 sands, high oil production rates are dependent upon pumping the wells down.

The pilot project has excellent potential for increasing oil production without further increasing steam injection. All three horizontal producers have had high producing fluid levels over 1300 feet over the pump (FOP) for several months. Speeding up the pumping units on wells $\mathrm{J}-201, \mathrm{~J}-203$ and $\mathrm{J}-205$ to draw down the fluid levels should increase production to about 2100 BPD gross and 115 BOPD per well (incremental of 800 BPD gross and 65 BOPD, $8.1 \%$ oil cut) based on leaving a safe producing fluid level to prevent sand inflow. Well FRA-29 was converted to injection in November 2000 to provide the necessary water injection support for production increases in wells $\mathrm{J}-201$ and J-203. This well will also provide more reservoir pressure support from outside the pilot area to improve well productivity similar to the flank water injection in the Tar II-A project. Additional water injection on the south flank of the project is needed to support increasing production in well $\mathrm{J}-205$ as shown in Figure 1.

Pilot production in December 2000 was 304 BOPD. The proposed work could increase oil production by 345 BOPD. Assuming an average steam injection rate of 3300 BCWESPD, the projected pilot oil rate of 649 BOPD would give a steam-oil ratio of 5.08 , which appears very reasonable.

\section{Shale Compaction Study:}

Operational management is focused on the apparent steamflood-related surface subsidence for the Tar II-A project due to shale compaction above the "D" sands. A study has been performed to confirm steamflood-related shale compaction, to determine where this phenomenon is occurring, to measure the extent of shale failure and identify the critical temperatures and reactions that occur during shale failure.

David K. Davies and Associates, Inc (DKD) analyzed both the pre-steam cores from well OB2-3 and the pre- and post-steam cores from wells OB2-5 and UP-908. DKD concluded that the most serious shale compaction is occurring in a six foot interval above the D1 sands as was conjectured. Lesser forms of shale compaction are occurring above and throughout the T2 sand, the thickest of the T sands, and in the interbedded shales within the upper D1 sands above the apparent steam / oil interface as delineated by the 
density - neutron log crossovers in the post-steam wells.

The study suggests that the shale compaction process occurs in two stages, an early compaction stage and a late compaction stage. The early compaction stage is a result of a relatively gradual expulsion of fluids from the shales through the matrix pore system into the surrounding sand laminations and its overall subsidence effect is minor. The late compaction stage is a result of fluid expansion causing pore pressures to build up high enough to cause hydraulic microfracturing throughout the shale matrix and its overall subsidence effect can be severe.

Using the seven compaction indicators given in the report, late stage shale compaction occurred in well OB2-5 from $2412.5-2440.15 \mathrm{ft}$ (above and throughout T2 sand), from 2531.5 - $2534.8 \mathrm{ft}$ (above D1 sand) and in the interbedded shales within the D1 sands to a depth of $2542 \mathrm{ft}$ which is above the steam / oil contact. The most impacted samples were above the D1 sands. According to the density-neutron log, the steam chest (log separation) in the T2 sand extended throughout the sand from 2417-2446 ft and the D1 sand steam chest also extended throughout the sand from 2535-2587 ft with a major log separation from 2535-2550 ft. In UP-908, the shales exhibited late stage compaction from 2558.25 - $2561.75 \mathrm{ft}$ (above D1 sand). The ReSpec core sample that was heated to $550^{\circ} \mathrm{F}$ also experienced late stage shale compaction. Early stage compaction was observed in most of the shales that experienced reservoir heating and in the ReSpec core sample that was heated to $275^{\circ} \mathrm{F}$. Recent Thermal-Decay-Time logs run in wells UP-800 and $1 \mathrm{~F}-10$ only show noticeable compaction in the twelve foot interval above the D1 sands and none in the "T" sands or interbedded shales in the "D1" sands, even when comparing total gross sub-zone thicknesses with the original logs.

The temperature ranges for the early and late compaction stages have not been clearly defined, but evidence uncovered to date can place some temperature limits on the processes. For early stage compaction, clay dewatering is known to start at $60^{\circ} \mathrm{C}$ or $140^{\circ} \mathrm{F}$. The ReSpec core sample that was heated to $135^{\circ} \mathrm{C}$ or $275^{\circ} \mathrm{F}$ experienced clay dewatering but not late stage compaction symptoms. Based on paleo-thermometry, a sample of post-steamflooded core in well OB2-5 experienced mineral transformations (chlorites and vitrinite reflectance values) indicative of late stage compaction. The core underwent minimum temperatures of $192-202^{\circ} \mathrm{C}\left(398-416^{\circ} \mathrm{F}\right)$ to create chlorites and could not have experienced temperatures above $280^{\circ} \mathrm{C}$ or $536^{\circ} \mathrm{F}$ or else the chlorites would have dissolved. Vitrinite is a kerogen-based hydrocarbon that provides reflectance values of the highest temperatures it encounters. The vitrinite reflectance values further reduced the upper range to $250^{\circ} \mathrm{C}$ or $482^{\circ} \mathrm{F}$. Yet as mentioned above, the crude oil tends to coke at approximately $285^{\circ} \mathrm{C}$ or $545^{\circ} \mathrm{F}$ and epidotes commonly form at $260-270^{\circ} \mathrm{C}$ or $500-518^{\circ} \mathrm{F}$, so discrepancies still exist. Therefore, it is safe to conclude that early stage compaction starts at $60^{\circ} \mathrm{C}$ or $140^{\circ} \mathrm{F}$ and late stage compaction starts between $135-192^{\circ} \mathrm{C}$ or 275 $398^{\circ} \mathrm{F}$. The upper temperature limits cannot be determined, other than to conclude it is below the steam injection temperature of $316^{\circ} \mathrm{C}$ or $600^{\circ} \mathrm{F}$ or to assume the maximum thermal reservoir simulation model temperature of $273^{\circ} \mathrm{C}$ or $523^{\circ} \mathrm{F}$ in the shales at the end of steamflood injection. These findings indicate that more ReSpec-type "open" shale compaction tests should be performed, perhaps at $177^{\circ} \mathrm{C}$ and $218^{\circ} \mathrm{C}\left(350^{\circ} \mathrm{F}\right.$ and $425^{\circ} \mathrm{F}$, respectively), to determine the critical microfracture temperature and measure the physical expansion and contraction of the samples.

With respect to the ReSpec "open-system" high temperature compaction tests on sands and shales, where fluids were allowed to bleed off to maintain constant pressures, the tests on the shales were probably closer to a "semi-closed" system because of the lack 
of vertical permeability in the samples. During the shale tests at $275^{\circ} \mathrm{F}$ and $550^{\circ} \mathrm{F}$, both samples were allowed to bleed fluids out of the system to maintain constant pressure in the test vessel. However, the rate of fluid expulsion was not recorded and therefore it cannot be determined when, if at all, the pore pressures exceeded critical lithostatic pressures and a resultant sudden release of pore fluids occurred. The sample heated to $550^{\circ} \mathrm{F}$ appears to have microfractures whereas the sample heated to $275^{\circ} \mathrm{F}$ did not. The test procedure also ramped up whole core temperatures within an hour, which may not have allowed the "whole core-size" shale samples to heat up uniformly and to "gradually" bleed off pressure to adjacent interbedded sands as would happen in the field. In the ReSpec shale test at $275^{\circ} \mathrm{F}$, compaction was based on early stage compaction symptoms or mostly through dehydration of the clays. The ReSpec shale test at $550^{\circ} \mathrm{F}$ underwent late stage compaction symptoms such as microfracturing, color changes, and mica realignment. Further shale tests at ReSpec should measure the rate of fluid expulsion from the core samples and ramp up temperatures more gradually to allow the large shale samples to heat up more uniformly.

\section{Technology Transfer}

Scott Hara of Tidelands and Don Clarke of the City organized the first annual "Petroleum Operations Day for Teachers and Community Leaders" held on November 10, 2000 in Long Beach². This event was open to all teachers and community leaders in Los Angeles and Orange Counties and the purpose was to introduce them to oil production and refinery operations. The whole day event included several oral presentations (Scott, Don and Mark Shemaria each made a presentation along with others), two field trips to one of the THUMS oil operating islands and to the Tosco Oil Refinery in Carson, and a large packet of oil and gas industry information and gifts. The event was attended by 38 teachers and community leaders and was well received.

Scott Hara reprised his presentation entitled "A Well Completion Technique for Controlling Unconsolidated Sand Formations by Using Steam" at the 2000 IPAA Mid-year Meeting, San Francisco, CA, May $18-20^{3}$. This was inadvertently missed in the $2^{\text {nd }}$ Qtr 2000 report.

A project homepage can be viewed on the Internet at http://www.usc.edu/dept/peteng/topko.html. A CD-ROM of the project on IBM PC format will be distributed free upon request to Scott Hara, Tidelands Oil Production Company, phone - (562) 436-9918, email - scott.hara@tidelandsoil.com.

\section{References and Notes}

1. Mondragon, J.J. III, Ershaghi, I., and Yang, Z., USC, "Post Steamflood Reservoir Management Using a Full-Scale Three-Dimensional Deterministic Thermal Reservoir Simulation Model, Wilmington Field, California", SPE Paper \#62571, 2000 AAPG / SPE Western Regional Meeting, Long Beach, CA, June 19-22.

2. Hara, Scott and Shemaria, Mark, Tidelands, Clarke, Don, City of Long Beach, 2000 Petroleum Operations Day for Teachers and Community Leaders, SPE Los Angeles Basin Section, Los Angeles Basin Geological Society, Tidelands, and THUMS Long Beach Company, Long Beach, CA, November 10. 
3. Scott Hara reprised his presentation entitled "A Well Completion Technique for Controlling Unconsolidated Sand Formations by Using Steam" at the 2000 IPAA Mid-year Meeting, San Francisco, CA, May 18-20. 